\title{
Tardigrades and their emergence as model organisms
}

\author{
Bob Goldstein \\ Department of Biology and Lineberger Comprehensive Cancer Center, University of North \\ Carolina at Chapel Hill, North Carolina 27599 USA \\ bobg@unc.edu \\ https://orcid.org/0000-0001-6961-675X
}

\begin{abstract}
Experimentally tractable organisms like C. elegans, Drosophila, zebrafish, and mouse are popular models for addressing diverse questions in biology. In 1997, two of the most valuable invertebrate model organisms to date $-C$. elegans and Drosophila - were found to be much more closely related to each other than expected. C. elegans and Drosophila belong to the nematodes and arthropods respectively, and these two phyla and six other phyla make up a clade of molting animals referred to as the Ecdysozoa. The other ecdysozoan phyla could be valuable models for comparative biology, taking advantage of the rich and continual sources of research findings as well as tools from both $C$. elegans and Drosophila. But when the Ecdysozoa was first recognized, few tools were available for laboratory studies in any of these six other ecdysozoan phyla. In 1999 I began an effort to develop tools for studying one such phylum, the tardigrades. Here, I describe how the tardigrade species Hypsibius exemplaris and tardigrades more generally have emerged over the past two decades as valuable new models for answering diverse questions. To date, these questions have included how animal body plans evolve and how biological materials can survive some remarkably extreme conditions.
\end{abstract}

Keywords: emerging model organisms; tardigrades; Hypsibius exemplaris; evo-devo; survival of extremes; protectants

\section{Emergence of a model system: a personal history}

My interest in tardigrades was sparked by a discovery made by others. In 1997, Anna Marie Aguinaldo and her colleagues reported an 18S rDNA molecular phylogeny of the metazoa, which revealed that nematodes and arthropods form a single clade together with other phyla of animals that periodically shed their exoskeletons (Aguinaldo et al., 1997). They dubbed this clade the Ecdysozoa, or molting animals. Broader phylogenomic studies later buttressed this finding (see Giribet and Edgecombe, 2017 for review), supporting the emerging realization that C. elegans (a nematode) and Drosophila (an arthropod) were much more closely related than had been thought. Before 1997, Drosophila was thought to be even more closely related to humans than to $C$. elegans (Sidow and Thomas, 1994). As a result, there were no reasonable options for studying groups of closely related animals that were also among the strongest 
genetic model systems unless one turned to the vertebrates, which were more cumbersome to study than invertebrate models like $C$. elegans and Drosophila.

In my PhD and first postdoc, I had used C. elegans as a model organism for uncovering fundamental mechanisms of development. Like many scientists with some curiosity about how developmental programs evolved, for nearly every developmental mechanism I thought about, I wondered if evolution had tinkered with that mechanism in ways that might have contributed to the evolution of animal body plans. When the Aguinaldo et al. 1997 paper was published, I was in a second postdoc, working on an evolution-of-development (evo-devo) project that was largely predicated on the old animal phylogeny. The 1997 paper forced me to re-think my plans.

Several labs at the time were already using arthropods other than Drosophila, or nematodes other than C. elegans, as comparative models in evo-devo, with success (for reviews see (Patel, 1994; Félix, 1999; Sommer, 2000; Carroll et al., 2001). Evo-devo was widely considered to encompass some of the greatest unsolved mysteries in developmental biology, but one for which future progress was expected to be challenging (Barinaga, 1994). Yet these labs were transforming evo-devo research, in two major ways: (1) by identifying key genes whose expression patterns could help identify homologous structures in extant organisms, and thus help trace paths of evolution, and (2) by identifying some of the developmental mechanisms that had been modified through evolution to diversify animal body plans. The genes and mechanisms studied by these labs were, for the most part, those that had conserved functions across a great breadth of animals. Choosing such highly conserved genes and mechanisms for lab study was in large part a practical issue: the likelihood was high that such genes and mechanisms would have conserved and interpretable functions in less-studied animals. As a result, a small number of genes with deeply-conserved functions, such as Hox genes, were frequently recurring themes in evo-devo studies.

I imagined that using an ecdysozoan relative of $C$. elegans and Drosophila, but outside of the nematode and arthropod phyla, might allow future researchers to maximally make use of both C. elegans and Drosophila as comparative model systems when asking how developmental mechanisms evolve. I pictured a large and continually growing menu of genes and mechanisms that could be productively studied to address interesting questions in comparative biology in general, and in evo-devo in particular. C. elegans and Drosophila researchers would likely pour out new findings continually, serving as fountains for future comparative studies on related nonmodel organisms. Some of the methods developed for studies of $C$. elegans and Drosophila might feasibly work in a close ecdysozoan relative as well. Unfortunately, there had been almost no modern, molecular work on development in the other ecdysozoan phyla, with only rare exceptions (see Grenier et al., 1997 for example). The other ecdysozoan phyla - the loriciferans, priapulids, onychophorans, nematomorphs, kinorhynchs, and tardigrades - were some of the least studied major groups of animals. Few tools existed for studying development in these animals. Even old descriptive literature on development in these phyla, dating from before much of developmental biology research had become focused on just a handful of genetic model organisms, was meager (Grassé, 1949, 1965; Hyman, 1951). 
In 1999 I began a lab at UNC Chapel Hill. I had equipped the lab with two microscopes for automated, multiplane DIC imaging of living C. elegans embryos (Thomas et al., 1996). These microscopes also seemed ideally suited to the kind of descriptive embryology that might be valuable for attempting some foundational work on a little-studied phylum. Lab members used these microscopes for $C$. elegans experiments, but the $C$. elegans films were generally short, leaving the microscopes rarely in use overnight. I decided to try getting my hands on a littlestudied ecdysozoan to film their embryos overnight on some nights, to see if I could collect data on normal development. The list of non-nematode, non-arthropod ecdysozoan phyla included mostly organisms I had never seen, but I had encountered tardigrades in an undergraduate course on animal diversity, and I had collected them from moss before. I went outside the lab and found some tardigrades, and I bought some tardigrades from multiple biological supply companies. I contacted tardigrade biologists Diane Nelson, Harold Heatwole, and Jette EibyeJacobsen for advice, and they kindly offered me tips on finding animals and keeping them alive in the lab. Among the tardigrade species I gathered and filmed, I looked for ones with small, optically clear embryos, and lacking ornate embryonic envelopes, so that I could film development by DIC microscopy and record patterns of cell divisions. I also wanted a species that had embryos with small cells and fast cell division cycles, because these features correlate at least very roughly with small genome size (Gregory and Hebert, 1999; Gregory, 2001). I envisioned that a large and potentially highly duplicated genome would make future gene function studies more difficult than would a compact genome. Looking ahead to gene function studies in tardigrades at this stage was highly wishful, since at this stage, sequences from only six genes existed in Genbank for the entire tardigrade phylum.

A species of tardigrades sold by Bob McNuff appeared suitable (Figure 1). Bob single-handedly ran a small biological supply company, Sciento, from his home or at times, from a lab that he had assembled in a shed behind his home near Manchester, England. Mark Blaxter's lab had started collecting some sequence data from this species and other tardigrade species (Goldstein and Blaxter, 2002; Blaxter et al., 2004). Embryos of this species were small, about the length of a $C$. elegans embryo (about $60 \mu \mathrm{m}$ ), and I could see cells dividing every $\sim 50$ minutes. The generation time was short - just 13-14 days - and I found that cultures could be frozen long-term and successfully revived. Although little work had been done with tardigrade embryos in the previous 60 years, near this time a second group published on the development of another tardigrade species, Thulinius (formerly Thulinia) stephaniae. The Thulinius embryos could replace ablated parts and lacked stereotyped patterns of cell divisions (Hejnol and Schnabel, 2005). In the species I was filming, I found invariant patterns of unequal cell divisions and nuclear migrations (these patterns are detailed further below). These invariant features made it possible to identify the same cells in each embryo, and hence to begin to recognize additional stereotyped features of early development, including stereotyped cell cycle periods in different cells. I sent some animals of the species I was filming to tardigrade biologist Roberto Bertolani, who kindly agreed to identify them: among previously-described tardigrade species, they most closely resembled Hypsibius dujardini. This species is composed primarily of females that can develop by parthenogenesis (in which eggs develop in the absence of mating or sperm; hence all-female cultures can be kept). Males also exist in this species but are rarely found (Ammermann, 1967; Bertolani, 2001). In our cultures, we have yet to recognize a male. 
After we had published several papers on this species (discussed below), other scientists seeking to improve the characterization of Hypsibius dujardini collected animals from as close to their original 1840 collection site near Paris (Doyère, 1840) as they could find them and discovered that the Parisian species they observed and the species sold by Bob McNuff were distinct (Gąsiorek et al., 2018). They concluded that we, and by this time several other labs, had likely been working on a previously undescribed species - probably a close relative of Hypsibius dujardini rather than Hypsibius dujardini itself. They dubbed the species Hypsibius exemplaris, for "exemplar", or "model", in recognition of the by-then "wide use of the species as a laboratory model for various types of scientific studies" (Gąsiorek et al., 2018). For this reason, pre-2018 literature on Hypsibius exemplaris uses the name Hypsibius dujardini, often also referring to Bob McNuff or his company Sciento as the source of animals used, or using the Sciento catalog number Z151 as the strain designation (see Goldstein, 2018 and Gąsiorek et al., 2018 for lists of the pre-2018 papers). Post-2018 literature uses the name Hypsibius exemplaris. Literature from before 2004 - before Bob McNuff's cultures began to enter the scientific literature - and that referred to Hypsibius dujardini (or with an earlier synonymous genus designation) may have used any of several possible species (for example Kaufmann, 1851; Marcus, 1929; Ammermann, 1967; see Gąsiorek et al., 2018 for a discussion of relevant clues).

\section{Tardigrades}

Tardigrades, also known as water bears, are a phylum of 8-legged microscopic animals. Although tardigrades are less well known to many scientists than the more widely-used model organisms, they have been known to science for almost as long as microscopic life has been known. Tardigrades were first described by several scientists in the 1770s (see Greven, 2018 for review).

1380 living tardigrade species have been recognized in the phylum to date (Guidetti and Bertolani, 2005; Degma and Guidetti, 2007; Degma et al., 2021), and it is likely that at least this many species again have yet to be discovered and described (Guil and Cabrero-Sañudo, 2007; Bartels et al., 2016). Tardigrades are most often placed by phylogenetic methods as a sister taxon to the arthropods plus onychophorans (see Giribet and Edgecombe, 2020 for review). This placement on the tree of life implies that tardigrades must have first arisen more than 500 million years ago.

Tardigrades live nearly everywhere on earth, although they are often overlooked because they are small (typically less than $1 \mathrm{~mm}$ long) and often transparent. Some tardigrade species live in marine sediments, and many live in water films in soil. Clean biological substrates that harbor water films, like mosses and lichens, are easy places to find tardigrades, perhaps primarily because collecting from clean substrates obviates the need to search among sediments. On mosses and lichens, tardigrades are often found together with nematodes and rotifers - which also possess the rare ability to survive drying, and hence that might be carried onto these surfaces by wind (Nkem et al., 2006; Ptatscheck et al., 2018; Rivas et al., 2019). Many tardigrades feed on algae or on microscopic animals, using piercing mouthparts and a muscular pharynx to suck cytoplasm out of these organisms (see Møbjerg et al., 2018 for review). 
Tardigrades have a simple body plan (Figures 2, 3, and Supplementary Video 1) and the same major tissue types as most other animals (Møbjerg et al., 2018; for details of Hypsibius exemplaris anatomy, see for example Mayer et al., 2013; Smith and Jockusch, 2014; Smith et al., 2017; Gross et al., 2019; Gross and Mayer, 2019; Richaud et al., 2020; Jezierska et al., 2021). The body has a tube-within-a-tube organization that is typical of most animals, in which a one-way digestive tract runs through the center of an elongated body. The gonad connects to the posterior digestive tract, along with malpighian tubules that function in osmoregulation. The fluid-filled body cavity that lies between the epidermis and digestive tract typically has hundreds of freely moving cells inside, called storage cells. Muscles criss-cross the body cavity, which functions as a hydrostatic skeleton. Each of the eight legs has several muscle cells extending into it from multiple directions, and connecting to the body wall, which dimples inward at each muscle attachment site. The nervous system includes a pair of eyespots, an anterior brain, and a ladder-like arrangement of paired segmental ganglia along the ventral side of the body. Major elements of the body plan become apparent during embryogenesis (Gabriel et al., 2007; Gross et al., 2017).

Tardigrades are famous for surviving extreme environments. When dried, many species of tardigrades lose nearly all of their intracellular water (Crowe, 1972; Richaud et al., 2020) and form a compact "tun" form that can remain desiccated for years and yet revive upon rehydration (Jørgensen et al., 2007; Schill and Hengherr, 2018; Richaud et al., 2020). In the desiccated state, the animals can survive extremes of pressure, temperature, and radiation, and they can survive extremes of radiation in the hydrated state as well (see Schill, 2018 for review).

\section{Early descriptions of tardigrade development}

Literature on development in tardigrades was scant when I began filming embryos. Four articles, all from before 1930, described embryos of different tardigrade species throughout much of embryonic development (Kaufmann, 1851; von Erlanger, 1895; von Wenck, 1914; Marcus, 1929). To my knowledge, the embryonic development of a tardigrade had never been described until the 1851 article, which included drawings of living embryos at 18 stages from early cell divisions through hatching (Kaufmann, 1851). The article also included a drawing of a tardigrade in the midst of releasing eggs into her own molt. Kaufmann's observations established some key facts for the species he observed that also hold for all tardigrade species observed to date. The embryos underwent apparently complete embryonic cell divisions (rather than producing a syncytium, as occurs in some arthropods). Early divisions produced daughter cells of at least approximately equal sizes. Development appeared to be direct, i.e. the animal that hatched at the end of embryonic development looked like a small tardigrade, rather than transitioning through a larva of a very different form before taking on the familiar form of a tardigrade. In 1895, the Baron Raphael Slidell von Erlanger noted a more than 40 year gap since Kaufmann's description of embryos and produced a set of color illustrations of embryos of a different species, through germ layer and organ formation, based on fixed and cleared samples (Von Erlanger, 1895). von Erlanger's illustrations were only diagrammatic, and he did not follow up on this work because he died of pneumonia two years later at age 32. In 1914, 
Wanda von Wenck reported on whole and sectioned embryos of what may have been a third species (von Wenck, 1914). And in 1929, Ernst Marcus described the development of Hypsibius dujardini or a closely related species (Gąsiorek et al., 2018) based in part on his sections of embryos (Marcus, 1929) (Marcus' slides bearing sectioned embryos later became part of the Smithsonian Natural History Museum's collection; the slides were deaccessioned by Smithsonian scientists in 2016 because of the slides' mixed quality by then, and they gave them to me).

\section{Raising Hypsibius exemplaris cultures in a lab}

Long-term culturing of tardigrades in labs has faced some challenges (Altiero and Rebecchi, 2001). Some tardigrade species had been maintained in labs before I began filming tardigrade embryos, but in at least some of the early papers it was not clear if long-term culturing had been used, or if animals had been re-collected periodically from the wild. Some tardigrade species are still repeatedly collected from the wild for studies, and reliable long-term wild sources of animals make this a practical option for certain species (Rebecchi et al., 2009 for example). I was surprised when Bob McNuff told me by phone in 2001 that he did not re-collect his animals from the wild periodically. Rather, he had been growing his cultures continuously for 14 years at the time, since collecting them in 1987. Bob's cultures may have represented the longest continuously maintained cultures of any tardigrade species to date, suggesting promise for indefinite lab maintenance of cultures - a valuable feature for any model organism. Bob kindly shared his methods for growing animals. Lab culture methods have been developed for other tardigrade species as well (Suzuki, 2003; Horikawa et al., 2008; Tsujimoto et al., 2015; Altiero et al., 2015). We have continued to focus most of our studies on Hypsibius exemplaris because of several advantages they offer over other tardigrade species for the questions we have addressed, including their clear embryos, consistently successful embryonic development in the lab, and their short and consistent embryonic development period and generation time (Goldstein, 2018; Yoshida et al., 2019). Still, some other tardigrade species offer some attractive features including even more compact genomes, a constitutive production of some protectants that contribute to survival in extremes, and an availability of males that might make classical genetics possible (Ramazzotti and Maucci, 1995; Suzuki, 2008; Bemm et al., 2017; Boothby et al., 2017; Yoshida et al., 2017).

Hypsibius exemplaris cultures can be maintained in labs at room temperature in petri plates (or in shallow cultures in Erlenmeyer flasks) in commercial spring water, feeding the animals an immotile, unicellular alga. At 1- to 2-week intervals we replace the water and algae. This can be done by pipetting liquid in cultures up and down to disperse old algae. Then we let the tardigrades settle for about a minute, then pour off most of the liquid and the dispersed algae, and add back more spring water, repeating this a few times to remove most of the old algae. Then we add spring water and some of a healthy culture of unicellular algae as fresh food. Alternatively, animals can be simply swirled to the center of a petri plate and pipetted into a plate with fresh spring water and algae. Bob McNuff is listed (together with his then-home address) as second author on one of our early papers based on his contributing methods for 
culturing animals long term (Gabriel et al., 2007; see McNuff, 2018 for a fuller description of Bob's collection site and culture methods). His work has highlighted that one can make an important contribution to science even without the myriad benefits of an institute or an institutional affiliation.

In cultures or on slides under microscopes, embryos develop to hatching in 4 to 4.5 days (Gabriel et al., 2007; Vasanthan and Stone, 2020). The resulting juvenile animals feed and grow for approximately 8 to 9 more days before they begin to lay embryos of their own. Gravid animals lay embryos into their own molts (often called an exuvia; "exuvia" is singular, "exuviae" is plural). The mothers exit their molts soon after laying, typically when the embryos are at the 1to 2-cell stage, leaving the embryos behind in the molts. The resulting clutches of nearlysynchronous embryos encased in transparent molts are ideal for microscopy of multiple living embryos simultaneously (Gabriel et al., 2007; Heikes and Goldstein, 2018). In diverse animals, molting permits growth beyond the constraints of a molt's size, but because the embryos of Hypsibius exemplaris are a significant fraction of the mother's body volume, the mother that leaves the molt after laying is smaller than the molt. Growth occurs as the mothers feed in the days between each laying. This laying and molting cycle repeats every $\sim 5$ days. Clutch size varies, likely depending on algal quality and/or on other food added in some cases, and varying with the age of the mother: clutches of 2-5 embryos are common, but with a range from 1 embryo to as high as 10-11 embryos (Gabriel et al., 2007; Vasanthan and Stone, 2020) or even more (Gąsiorek et al., 2018).

\section{Our early descriptive work on the animals and their development}

I worked on tardigrades mostly alone in my lab among the graduate students and postdocs working on C. elegans until 2003, when one graduate student, Willow Gabriel, began to focus on tardigrades for her PhD project. Willow developed embryo immunostaining methods and reported the first immunolocalization data in the phylum, using cross-reactive antibodies from Nipam Patel (Gabriel and Goldstein, 2007). Willow used the data she collected to begin to address questions about segmentation mechanisms. She also produced a staging series for the embryos, describing embryonic development from DIC films and from fixed, DAPI-stained embryos. We published the staging series together with several other findings that helped establish a platform for further work on the system (Gabriel et al., 2007). For example, collaborator T. Ryan Gregory contributed a genome size estimate based on Feulgen densitometry and propidium iodide flow cytometry, suggesting a compact genome of about 75 megabases, which is at least roughly in line with the current estimate of 104 megabases in the best current genome assembly (Yoshida et al., 2017). We saw five pairs of chromosomes, the same number that had been reported previously for Hypsibius dujardini (Ammermann, 1967). We also reported on cell division patterns in the early embryo, and we related these patterns to the body axes. The first mitosis produced anterior and posterior daughter cells, although with no apparent indication at the two-cell stage of which cell is which (we can recognize these cells as anterior vs. posterior daughter cells only retrospectively, in films that last until anterior and posterior ends are apparent when the embryo begins to elongate within its eggshell). At the 4- 
cell stage, I found that the nuclei in two of the four cells consistently migrated toward a common cell-cell boundary, and the two cells harboring these nuclei then divided unequally, producing a slightly smaller daughter cell near the cell-cell boundary toward which nuclear migration had occurred. This pattern of nuclear migrations and unequal divisions repeated for multiple rounds of division, and the site where this occurred became consistently the ventral side of the embryo. These observations contributed to an initial draft of an early-stage cell lineage, although without cell fates indicated, because we had no cell fate markers yet that we could relate reliably to the positions of lineaged cells (Gabriel et al., 2007). Current work in the lab is revising some features of the published cell lineage using observations of more embryos and assigning one of the major cell fates on the lineage by the molecular identification of the germline precursor cells.

\section{The tardigrade toolbox: resources for tardigrade research}

To enable mechanistic studies using tardigrades as a model, we needed to develop several tools for the first time in the phylum. We developed methods for immunolocalization (Gabriel et al., 2007; Smith and Gabriel, 2018), in situ hybridization (Smith et al., 2016; Smith, 2018), live microscopy of embryos using DIC microscopy or fluorescent cell staining (Gabriel et al., 2007; Heikes and Goldstein, 2018; McGreevy et al., 2018; Figure 4), microinjection of animals (Tenlen et al., 2013; Tenlen, 2018), RNA interference (Tenlen et al., 2013; Tenlen, 2018), and methods for identifying proteins that mediate tolerance to desiccation (Boothby et al., 2017). We share methods openly in order to help build a community of researchers that can answer key scientific questions more efficiently. We have shared protocols on our lab website, in publications, and as a volume of Hypsibius exemplaris protocols in the Cold Spring Harbor Emerging Model Systems series (Goldstein, 2018).

The best current Hypsibius exemplaris genome assembly is fairly complete in terms of genes found compared to benchmark gene sets, and partially assembled: half of the genome is represented in 85 scaffolds of 342 kilobases or larger, and $90 \%$ of the genome is represented in 343 scaffolds of 65 kilobases or larger (Yoshida et al., 2017). We published a draft genome in 2015 and presented evidence of extensive horizontal gene transfer, but our conclusion was soon disproven (Boothby et al., 2015; Koutsovoulos et al., 2016; Bemm et al., 2016; Delmont and Eren, 2016; Arakawa, 2016; Arakawa et al., 2016; Yoshida et al., 2017). Yoshida and coauthors demonstrated that gene prediction software can produce a systematic elevation of horizontal gene transfer predictions, which likely accounted for some of the elevated rate we inferred (Yoshida et al., 2017). Because our assembly included contaminants, they incorporated our sequence data in the current assembly only where our reads mapped to their own initial assembly (Yoshida et al., 2017). Perhaps the most convincing data disproving our hypothesis of elevated horizontal gene transfer was the genome sequencing of individual tardigrades that had been starved to clear their intestinal contents for 48 hours, in the presence of antibiotics, and without filtering resulting reads for predicted contaminants (Arakawa, 2016; Arakawa et al., 2016). These data together with Yoshida and coauthors' reassembly indicate that horizontal gene transfer has occurred in tardigrades only at a rate that is typical for animals, and the data provide a fairly complete and partially assembled genome that serve as a valuable platform for 
further studies using the organism (Yoshida et al., 2017). The genomes of two other tardigrade species have also been sequenced: Ramazzottius varieornatus (Hashimoto et al., 2016) and Milnesium tardigradum (Bemm et al., 2017).

Perhaps the methods most needed now for diverse kinds of further studies are transgenesis and CRISPR-mediated DNA editing. My lab's strategy for seeking to develop much-needed experimental tools, while maintaining a focus on our goal to answer scientific questions, has been to seek a balance: We have been opportunistic about addressing questions of deep interest that can be answered with the tools developed to date, while also seeking to spend a fraction of our time developing new methods. This strategy has afforded us a gradually improved understanding of the biology of the organism, and we hope that this improved understanding can make tool development increasingly efficient. We have also taken a 2-week period dedicated to methods development as a team, instigated and organized by lab member Kira Heikes with enthusiastic help from everyone involved. Our plan to repeat for two weeks each summer what we called "Camp Tardigrade" has been put on hold by the COVID-19 pandemic, temporarily.

\section{Using tardigrades to contribute to understanding of how animal body plans evolve}

Although our efforts with tardigrades were motivated by a vision of expanding the menu of genes and mechanisms that might be of interest beyond primarily the Hox genes and other deeply conserved developmental genes, once we had some tools in hand, we turned to Hox genes as an initial gene set of value for understanding homology of major body regions. Frank Smith visited the lab for a summer in the midst of his PhD work at the University of Connecticut to pursue his interest in developing an in situ hybridization method for tardigrades. He succeeded, and then he came back after his $\mathrm{PhD}$, where he made use of the method for his postdoc. To understand how a common ancestor diverged to produce diverse organisms including tardigrades, Frank established segment homologies by examining Hox gene expression patterns in Hypsibius exemplaris (Smith et al., 2016). Addressing this issue had the potential to shed light on the path of evolution that led to the origin of the tardigrade body plan. Hox genes whose expression patterns define the heads of arthropods and other animals were expressed in a similar anterior-posterior order in tardigrades. But we were surprised to see that the ordered expression pattern boundaries covered not just the tardigrade head but most of the tardigrade body, suggesting that much of the tardigrade body might be homologous to only the heads of arthropods and other animals. Frank found that a posterior Hox gene of animals was expressed in the posterior end of the tardigrade, abutting an expression pattern of a head Hox gene homolog, suggesting that a large region of the body in between had been deleted in evolution - a region corresponding to the entire thorax and nearly the entire abdomen of Drosophila. These results and the expression patterns of other regional identity genes, together with a loss of certain Hox genes in diverse tardigrade species, suggested that the body plan of an animal phylum - the compact body plan of tardigrades - can arise by the loss of a much larger part of an ancestor's body than we had anticipated (Smith et al., 2016). 
Frank used nervous system patterning genes to test a similar hypothesis about the evolution of nervous systems in tardigrades and their close relatives, the arthropods and onychophorans (Smith and Goldstein, 2016). The expression domains of nervous system patterning genes appeared to buttress the conclusion we reached on the basis of Hox gene expression: tardigrade homologs of genes that pattern arthropod brains are expressed in a similar anteriorto-posterior order in tardigrades as in arthropods, but with the three-segment brain of arthropods corresponding to a one-segment tardigrade brain plus the ganglia of the first two leg-bearing segments (Smith et al., 2018). Frank established his own lab at the University of North Florida, where he and his lab have found evidence from leg gap gene expression that limbs may have experienced a similar loss of a central region along with the loss of a major leg gap gene, Dac (Game and Smith, 2020). Together, these data build a working hypothesis that the tardigrade body plan may have arisen by the loss of major body parts of tardigrades' ancestors.

\section{Using tardigrades to contribute to understanding how biological materials can survive extremes}

Tardigrades have survived desiccation for decades, freezing to below $1 \mathrm{~K}$ (at which molecular motion is nearly stopped), heating to $151^{\circ} \mathrm{C}$, ionizing radiation at doses about 1000 times higher than humans or most animals can survive, and extremes of pressure including multiple-day exposure in the vacuum of space (see Schill, 2018 for review). Even in purified form, DNA, RNA, proteins, and other biological materials would be damaged or destroyed by some of these conditions - suggesting that tardigrades must harbor exceptional molecules that can protect them (referred to as protectants) and/or damage repair mechanisms. We are interested in understanding such protectants and repair mechanisms because of our fascination with how living organisms and biological materials can survive extremes and because of the practical potential for using biologically-derived substances as protectants for fragile drugs and medicines.

Until 2013, we had no way to disrupt gene functions in tardigrades, limiting our ability to identify roles for identified genes. Postdoc Jennifer Tenlen, with contributions from undergraduate student Shaina McCaskill, tried several methods for RNAi and found that injecting doublestranded RNA into Hypsibius exemplaris adults could result in the specific depletion of a targeted mRNA (Tenlen et al., 2013). Jennifer found that targeting different genes resulted in different phenotypes that depended on which gene was targeted, giving us some confidence in the specificity of RNAi in tardigrades. The method that Jennifer developed involves injecting double-stranded RNA into individual adults, which is labor intensive, but with practice, lab members have been able to inject up to $\sim 100$ animals in a day. We proposed that this development of an RNAi method for tardigrades could form a platform for discovering tardigrade gene functions, and that this ability to study gene functions could help advance our understanding of both the evolution of development and survival of extremes (Tenlen et al., 2013).

Postdoc Thomas Boothby used transcriptomics methods to identify Hypsibius exemplaris genes that become upregulated during desiccation (Boothby et al., 2017). Hypsibius exemplaris 
requires gradual drying to survive desiccation, and there is evidence that the animals mount a gene expression response to gradual drying that promotes their survival (Wright, 1989; Kondo et al., 2015; Boothby et al., 2017). Among the genes that Thomas found upregulated in response to drying was a set of Hypsibius exemplaris homologs of previously-identified intrinsically disordered tardigrade proteins, dubbed cytosolic-abundant, heat-stable proteins, or CAHS proteins (Yamaguchi et al., 2012). Thomas targeted CAHS-encoding genes by RNAi and found that this reduced the ability of animals to survive specifically when the animals were challenged with desiccation. As a step toward determining whether these proteins might be used to protect other biological materials, Thomas and collaborators expressed the genes encoding tardigrade CAHS proteins in bacteria or yeast and found that some of these genes could promote bacterial or yeast desiccation tolerance. Some of the CAHS proteins in buffer could also protect enzyme activities upon desiccation, freezing, or lyophilization (Boothby et al., 2017; Piszkiewicz et al., 2019). The proteins and the slow-dried tardigrades could form glassy solids - amorphous rather than crystalline solids - up to high temperatures, and the temperature above which a glassy state was lost roughly coincided with the maximum temperature that dried tardigrades, or yeast expressing these proteins, could survive. Other tardigrade species survive roughly up to the temperature at which they maintain a glassy state as well (Hengherr et al., 2009). Together, these results identified tardigrade proteins upregulated in response to desiccation and that contribute to desiccation tolerance, and they suggested a mechanism by which the proteins might work - by forming a glassy matrix that might prevent the disruption of other molecules during desiccation (Boothby et al., 2017; Boothby and Pielak, 2017).

Another group has searched for tardigrade proteins that can protect DNA from damage (Hashimoto et al., 2016). Hashimoto and colleagues biochemically purified tardigrade chromatin and identified some of the associated proteins. One such protein was found to localize to tardigrade DNA in immunostaining experiments and to colocalize with nuclear DNA when expressed in insect or human tissue culture cells. Interestingly, expression of this protein could suppress DNA damage in X-ray irradiated tissue culture cells and improve the viability of the irradiated cells. This work hence identified the first tardigrade-derived suppressor of DNA damage, and Hashimoto and colleagues dubbed the protein Dsup, for Damage suppressor. Dsup appears to be a tardigrade-specific protein, highlighting the value of turning to nontraditional model systems to identify proteins with extraordinary features (see Hashimoto and Kunieda, 2017 for review). Expressing Dsup in plants can also protect plant DNA from damage (Kirke et al., 2020). Understanding how Dsup suppresses DNA damage will be of interest. To date, it has been demonstrated that Dsup can bind nucleosomes, and it suppresses the potential for hydroxyl radicals - which can form when ionizing radiation splits water molecules to mediate cleavage of DNA (Chavez et al., 2019).

\section{Unanswered questions and future prospects}


The use of Hypsibius exemplaris as a model system for diverse studies has grown over the past 15 years (Figure 5). Here, I address some unanswered questions of broad interest for which Hypsibius exemplaris can serve as a valuable model.

Tardigrades and a handful of other animal groups survive both ecologically-relevant extremes as well as several more remarkable extremes, but the mechanisms by which they do so are only incompletely understood. For the protectants identified to date from tardigrades, including the CAHS proteins and Dsup, there is much yet to be learned about the biochemical mechanisms by which they can suppress damage (Tanaka et al., 2015; Hashimoto and Kunieda, 2017; Janis et al., 2018; Hesgrove and Boothby, 2020; Hibshman et al., 2020). And the potential for these protectants to be used to stabilize fragile protein-based medicines has only recently been explored. CAHS proteins, which have been perhaps the most explored in this regard, have not yet been found to generally outperform other proteins in stabilizing enzymes at least in conditions tested to date (Piszkiewicz et al., 2019). Modifying CAHS proteins might be a route to increasing their potency as stabilizers, and this approach might be taken with other proteins that can function as stabilizers as well (Piszkiewicz et al., 2019). CAHS proteins or other protectants might also be used to stabilize fragile vaccines or cells. One CAHS protein has been injected in mice, and this did not result in harmful lysis of red blood cells above a low level caused by routine injection of ringer's solution, and there were no signs of inflammation or toxicity, suggesting some promise in its use as a safe vaccine stabilizer (Esterly et al., 2020). Tardigrades are likely to harbor more protectants than are known to date, since different extreme conditions induce different gene expression responses, and protectants known to date are not known to protect against multiple extreme conditions (Boothby et al., 2017), nor to localize to every cellular compartment that would presumably need to be protected. As protectants are discovered, it will be fascinating to learn whether ancient protective mechanisms were retained in the rare animal groups that can survive extremes, or whether some protectants evolved such roles de novo.

Methods for transgenesis and CRISPR in tardigrades would be valuable for accelerating discovery of mechanisms used to survive extremes as well as a variety of other discoveries. RNA interference allows some studies of gene function, as discussed above, and chemical inhibitors have also been used to discover genes or pathways of interest from tardigrades (Kondo et al., 2015, 2019, 2020; Wojciechowska et al., 2021). To date, forward genetic screening using mutagenesis has not been reported.

Cultured cell lines have not been isolated from tardigrades, although there are cells that continue to divide in the adults of Hypsibius exemplaris, raising the attractive possibility of developing cell lines even from adults (Gross et al., 2018). If a cultured cell line that can survive extreme conditions could be developed from tardigrades, this could be valuable for studying cellular and molecular mechanisms of extreme tolerance, much as has been the desiccationtolerant Pv11 cell line from the midge Polypedilum vanderplanki (Nakahara et al., 2010; Sogame and Kikawada, 2017).

How the body form of a tardigrade is generated during embryogenesis, by specification of cell fates and body regions and the generation of segmental-like patterns, is not well understood at 
all. And although tardigrades likely lost major body regions that were present in ancestors, the developmental and evolutionary mechanisms that led to such losses are incompletely understood. Tardigrades will likely continue to be useful along with other organisms to help trace evolutionary changes in the arthropods and nematodes, and more generally to aid in establishing the gene complement, development, and morphology of ancestors at various nodes of animal phylogeny (see for example Bavan et al., 2009; Hering and Mayer, 2014; Gross and Mayer, 2015; Smith and Goldstein, 2016; Thiruketheeswaran et al., 2016; Hering et al., 2016; Nelson, 2017; Smith et al., 2017; Koziol, 2018; Mapalo et al., 2020).

Acknowledgments: I thank lab members to date who have made discoveries, developed novel ideas, and contributed to a stimulating and interactive environment for tardigrade work in the lab including Willow Gabriel, Sapna Patel, Jennifer Tenlen, Shaina McCaskill, Susan Clark, Thomas Boothby, Frank Smith, Kiera Patanella, Samantha Piszkiewicz, Sophia Tintori, Kristen McGreevy, Matt Niederhuber, Kira Heikes, Heather Barber, Emily Shaljian, Jonathan Hibshman, Courtney Clark-Hachtel, Sydney Lai, Noemi Gavino-Lopez, and Adriana Coke, many collaborators including Lorena Rebecchi and Bob McNuff, many MBL Physiology and Embryology course students, and Anna Marie Aguinaldo and colleagues for their clever use of animals with slow molecular clock estimates for reconstructing metazoan phylogeny. Our development of tardigrades as a model system has been supported by National Science Foundation grants IOS 0235658, IOS 1257320, IOS 1557432, and IOS 2028860.

\section{References}

Aguinaldo, A.M., Turbeville, J.M., Linford, L.S., Rivera, M.C., Garey, J.R., Raff, R.A., Lake, J.A., 1997. Evidence for a clade of nematodes, arthropods and other moulting animals. Nature 387, 489-493.

Altiero, T., Giovannini, I., Guidetti, R., Rebecchi, L., 2015. Life history traits and reproductive mode of the tardigrade Acutuncus antarcticus under laboratory conditions: strategies to colonize the Antarctic environment. Hydrobiologia 761, 277-291.

Altiero, T., Rebecchi, L., 2001. Rearing tardigrades: results and problems. Zoologischer Anzeiger-A Journal of Comparative Zoology 240, 217-221.

Ammermann, D., 1967. Die Cytologie der Parthenogenese bei dem Tardigraden Hypsibius dujardini. Chromosoma 23, 203-213.

Arakawa, K., 2016. No evidence for extensive horizontal gene transfer from the draft genome of a tardigrade. Proc. Natl. Acad. Sci. U. S. A. 113, E3057.

Arakawa, K., Yoshida, Y., Tomita, M., 2016. Genome sequencing of a single tardigrade Hypsibius dujardini individual. Sci Data 3, 160063.

Barinaga, M., 1994. Frontiers in biology: development. Science 266, 561-614.

Bartels, P.J., Apodaca, J.J., Mora, C., Nelson, D.R., 2016. A global biodiversity estimate of a 
poorly known taxon: phylum Tardigrada. Zool. J. Linn. Soc. 178, 730-736.

Bavan, S., Straub, V.A., Blaxter, M.L., Ennion, S.J., 2009. A P2X receptor from the tardigrade species Hypsibius dujardini with fast kinetics and sensitivity to zinc and copper. BMC Evol. Biol. 9, 17.

Bemm, F., Burleigh, L., Förster, F., Schmucki, R., Ebeling, M., Janzen, C.J., Dandekar, T., Schill, R.O., Certa, U., Schultz, J., 2017. Draft genome of the Eutardigrade Milnesium tardigradum sheds light on ecdysozoan evolution. bioRxiv. https://doi.org/10.1101/122309

Bemm, F., Weiß, C.L., Schultz, J., Förster, F., 2016. Genome of a tardigrade: Horizontal gene transfer or bacterial contamination? Proc. Natl. Acad. Sci. U. S. A. 113, E3054-E3056.

Bertolani, R., 2001. Evolution of the reproductive mechanisms in tardigrades-a review. Zoologischer Anzeiger-A Journal of Comparative Zoology 240, 247-252.

Blaxter, M., Elsworth, B., Daub, J., 2004. DNA taxonomy of a neglected animal phylum: an unexpected diversity of tardigrades. Proc. Biol. Sci. 271 Suppl 4, S189-92.

Boothby, T.C., Pielak, G.J., 2017. Intrinsically Disordered Proteins and Desiccation Tolerance: Elucidating Functional and Mechanistic Underpinnings of Anhydrobiosis. Bioessays 39, 1700119. https://doi.org/10.1002/bies.201700119

Boothby, T.C., Tapia, H., Brozena, A.H., Piszkiewicz, S., Smith, A.E., Giovannini, I., Rebecchi, L., Pielak, G.J., Koshland, D., Goldstein, B., 2017. Tardigrades Use Intrinsically Disordered Proteins to Survive Desiccation. Mol. Cell 65, 975-984.e5.

Boothby, T.C., Tenlen, J.R., Smith, F.W., Wang, J.R., Patanella, K.A., Nishimura, E.O., Tintori, S.C., Li, Q., Jones, C.D., Yandell, M., Messina, D.N., Glasscock, J., Goldstein, B., 2015. Evidence for extensive horizontal gene transfer from the draft genome of a tardigrade. Proc. Natl. Acad. Sci. U. S. A. 112, 15976-15981.

Carroll, S.B., Grenier, J.K., Weatherbee, S.D., 2001. From DNA to diversity: Molecular genetics and the evolution of animal design. Blackwell Science.

Chavez, C., Cruz-Becerra, G., Fei, J., Kassavetis, G.A., Kadonaga, J.T., 2019. The tardigrade damage suppressor protein binds to nucleosomes and protects DNA from hydroxyl radicals. Elife 8 . https://doi.org/10.7554/eLife.47682

Crowe, J.H., 1972. Evaporative water loss by tardigrades under controlled relative humidities. Biol. Bull. 142, 407-416.

Degma, P., Bertolani, R., Guidetti, R., 2021. Actual checklist of Tardigrada species (2009-2021: 19-07-2021) [WWW Document]. URL DOI: 10.25431/11380_1178608. (accessed 10.26.21).

Degma, P., Guidetti, R., 2007. Notes to the current checklist of Tardigrada. Zootaxa 1579, 4153.

Delmont, T.O., Eren, A.M., 2016. Identifying contamination with advanced visualization and analysis practices: metagenomic approaches for eukaryotic genome assemblies. PeerJ 4, e1839.

Doyère, M., 1840. Mémoire sur les Tardigrades, in: Annales Des Sciences Naturelles. pp. 269_ 361.

Esterly, H.J., Crilly, C.J., Piszkiewicz, S., Shovlin, D.J., Pielak, G.J., Christian, B.E., 2020. Toxicity and Immunogenicity of a Tardigrade Cytosolic Abundant Heat Soluble Protein in Mice. Frontiers in Pharmacology. https://doi.org/10.3389/fphar.2020.565969

Félix, M.A., 1999. Evolution of developmental mechanisms in nematodes. J. Exp. Zool. 285, 318.

Gabriel, W.N., Goldstein, B., 2007. Segmental expression of Pax3/7 and engrailed homologs in tardigrade development. Dev. Genes Evol. 217, 421-433.

Gabriel, W.N., McNuff, R., Patel, S.K., Gregory, T.R., Jeck, W.R., Jones, C.D., Goldstein, B., 2007. The tardigrade Hypsibius dujardini, a new model for studying the evolution of development. Dev. Biol. 312, 545-559.

Game, M., Smith, F.W., 2020. Loss of intermediate regions of perpendicular body axes 
contributed to miniaturization of tardigrades. Proc. Biol. Sci. 287, 20201135.

Gąsiorek, P., Stec, D., Morek, W., Michalczyk, Ł., 2018. An integrative redescription of Hypsibius dujardini (Doyère, 1840), the nominal taxon for Hypsibioidea (Tardigrada: Eutardigrada). Zootaxa 4415, 45-75.

Giribet, G., Edgecombe, D.G., 2020. The invertebrate tree of life. Princeton University Press.

Giribet, G., Edgecombe, G.D., 2017. Current Understanding of Ecdysozoa and its Internal Phylogenetic Relationships. Integr. Comp. Biol. 57, 455-466.

Goldstein, B., 2018. The Emergence of the Tardigrade Hypsibius exemplaris as a Model System. Cold Spring Harb. Protoc. 2018, 859-866.

Goldstein, B., Blaxter, M., 2002. Tardigrades. Curr. Biol. 12, R475.

Grassé, P.-P., 1965. Traite de zoologie: anatomie, systematique, biologie Tome 4, Fascicle 3. Masson., Paris.

Grassé, P.P., 1949. Ed. Traite de zoologie. Anatomie, systématique, biologie. Tome VI. Onychophores, Tardigrados, Arthropodes, Trilobltomorphes, Gbélicérates. Ed. Traite de zoologie. Anatomie, systématique.

Gregory, T.R., 2001. The bigger the C-value, the larger the cell: genome size and red blood cell size in vertebrates. Blood Cells Mol. Dis. 27, 830-843.

Gregory, T.R., Hebert, P.D., 1999. The modulation of DNA content: proximate causes and ultimate consequences. Genome Res. 9, 317-324.

Grenier, J.K., Garber, T.L., Warren, R., Whitington, P.M., Carroll, S., 1997. Evolution of the entire arthropod Hox gene set predated the origin and radiation of the onychophoran/arthropod clade. Curr. Biol. 7, 547-553.

Greven, H., 2018. From Johann August Ephraim Goeze to Ernst Marcus: A Ramble Through the History of Early Tardigrade Research (1773 Until 1929), in: Schill, R.O. (Ed.), Water Bears: The Biology of Tardigrades. Springer International Publishing, Cham, pp. 1-55.

Gross, V., Bährle, R., Mayer, G., 2018. Detection of cell proliferation in adults of the water bear Hypsibius dujardini (Tardigrada) via incorporation of a thymidine analog. Tissue Cell 51, 77-83.

Gross, V., Mayer, G., 2019. Cellular morphology of leg musculature in the water bear Hypsibius exemplaris (Tardigrada) unravels serial homologies. R Soc Open Sci 6, 191159.

Gross, V., Mayer, G., 2015. Neural development in the tardigrade Hypsibius dujardini based on anti-acetylated a-tubulin immunolabeling. Evodevo 6, 12.

Gross, V., Minich, I., Mayer, G., 2017. External morphogenesis of the tardigrade Hypsibius dujardini as revealed by scanning electron microscopy. J. Morphol. 278, 563-573.

Gross, V., Müller, M., Hehn, L., Ferstl, S., Allner, S., Dierolf, M., Achterhold, K., Mayer, G., Pfeiffer, F., 2019. X-ray imaging of a water bear offers a new look at tardigrade internal anatomy. Zoological Lett 5, 14.

Guidetti, R., Bertolani, R., 2005. Tardigrade taxonomy: an updated check list of the taxa and a list of characters for their identification. Zootaxa 845, 1-46.

Guil, N., Cabrero-Sañudo, F.J., 2007. Analysis of the species description process for a little known invertebrate group: the limnoterrestrial tardigrades (Bilateria, Tardigrada), in: Hawksworth, D.L., Bull, A.T. (Eds.), Vertebrate Conservation and Biodiversity. Springer Netherlands, Dordrecht, pp. 237-260.

Hashimoto, T., Horikawa, D.D., Saito, Y., Kuwahara, H., Kozuka-Hata, H., Shin-I, T., Minakuchi, Y., Ohishi, K., Motoyama, A., Aizu, T., Enomoto, A., Kondo, K., Tanaka, S., Hara, Y., Koshikawa, S., Sagara, H., Miura, T., Yokobori, S.-I., Miyagawa, K., Suzuki, Y., Kubo, T., Oyama, M., Kohara, Y., Fujiyama, A., Arakawa, K., Katayama, T., Toyoda, A., Kunieda, T., 2016. Extremotolerant tardigrade genome and improved radiotolerance of human cultured cells by tardigrade-unique protein. Nat. Commun. 7, 12808.

Hashimoto, T., Kunieda, T., 2017. DNA Protection Protein, a Novel Mechanism of Radiation Tolerance: Lessons from Tardigrades. Life 7. https://doi.org/10.3390/life7020026 
Heikes, K.L., Goldstein, B., 2018. Live Imaging of Tardigrade Embryonic Development by Differential Interference Contrast Microscopy. Cold Spring Harb. Protoc. 2018, 874-877. https://doi.org/10.1101/pdb.prot102335

Hejnol, A., Schnabel, R., 2005. The eutardigrade Thulinia stephaniae has an indeterminate development and the potential to regulate early blastomere ablations. Development 132, 1349-1361.

Hering, L., Bouameur, J.-E., Reichelt, J., Magin, T.M., Mayer, G., 2016. Novel origin of laminderived cytoplasmic intermediate filaments in tardigrades. Elife 5, e11117.

Hering, L., Mayer, G., 2014. Analysis of the opsin repertoire in the tardigrade Hypsibius dujardini provides insights into the evolution of opsin genes in panarthropoda. Genome Biol. Evol. 6, 2380-2391.

Hesgrove, C., Boothby, T.C., 2020. The biology of tardigrade disordered proteins in extreme stress tolerance. Cell Communication and Signaling 18, 178. https://doi.org/10.1186/s12964-020-00670-2

Hibshman, J.D., Clegg, J.S., Goldstein, B., 2020. Mechanisms of Desiccation Tolerance: Themes and Variations in Brine Shrimp, Roundworms, and Tardigrades. Frontiers in Physiology 11:592016. https://doi.org/10.3389/fphys.2020.592016

Horikawa, D.D., Kunieda, T., Abe, W., Watanabe, M., Nakahara, Y., Yukuhiro, F., Sakashita, T., Hamada, N., Wada, S., Funayama, T., Katagiri, C., Kobayashi, Y., Higashi, S., Okuda, T., 2008. Establishment of a rearing system of the extremotolerant tardigrade Ramazzottius varieornatus: a new model animal for astrobiology. Astrobiology 8, 549-556.

Hyman, L.H., 1951. Acanthocephala, aschelminthes, and entoprocta: the pseudocoelomate bilateria. McGraw-Hill, New York.

Janis, B., Belott, C., Menze, M.A., 2018. Role of Intrinsic Disorder in Animal Desiccation Tolerance. Proteomics 18, e1800067.

Jezierska, M., Miernik, A., Sojka, J., Student, S., Śliwińska, M.A., Gross, V., Poprawa, I., 2021. Oogenesis in the tardigrade Hypsibius exemplaris Gąsiorek, Stec, Morek \& Michalczyk, 2018 (Eutardigrada, Hypsibiidae). Micron 150, 103126.

Jørgensen, A., Møbjerg, N., Kristensen, R.M., 2007. A molecular study of the tardigrade Echiniscus testudo (Echiniscidae) reveals low DNA sequence diversity over a large geographical area. J. Limnol. 66, 77-83.

Kaufmann, F.J., 1851. Ueber die Entwicklung und systematische Stellung der Tardigraden. $Z$. Wiss. Zool. 3, 220-232.

Kirke, J., Jin, X.-L., Zhang, X.-H., 2020. Expression of a Tardigrade Dsup Gene Enhances Genome Protection in Plants. Molecular Biotechnology 62, 563-571. https://doi.org/10.1007/s12033-020-00273-9

Kondo, K., Kubo, T., Kunieda, T., 2015. Suggested Involvement of PP1/PP2A Activity and De Novo Gene Expression in Anhydrobiotic Survival in a Tardigrade, Hypsibius dujardini, by Chemical Genetic Approach. PLoS One 10, e0144803.

Kondo, K., Mori, M., Tomita, M., Arakawa, K., 2020. Pre-treatment with D942, a furancarboxylic acid derivative, increases desiccation tolerance in an anhydrobiotic tardigrade Hypsibius exemplaris. FEBS Open Bio 10, 1774-1781.

Kondo, K., Mori, M., Tomita, M., Arakawa, K., 2019. AMPK activity is required for the induction of anhydrobiosis in a tardigrade Hypsibius exemplaris, and its potential up-regulator is PP2A. Genes Cells 24, 768-780.

Koutsovoulos, G., Kumar, S., Laetsch, D.R., Stevens, L., Daub, J., Conlon, C., Maroon, H., Thomas, F., Aboobaker, A.A., Blaxter, M., 2016. No evidence for extensive horizontal gene transfer in the genome of the tardigrade Hypsibius dujardini. Proc. Natl. Acad. Sci. U. S. A. 113, 5053-5058.

Koziol, U., 2018. Precursors of neuropeptides and peptide hormones in the genomes of tardigrades. Gen. Comp. Endocrinol. 267, 116-127. 
Mapalo, M.A., Arakawa, K., Baker, C.M., Persson, D.K., Mirano-Bascos, D., Giribet, G., 2020. The Unique Antimicrobial Recognition and Signaling Pathways in Tardigrades with a Comparison Across Ecdysozoa. G3 10, 1137-1148.

Marcus, E., 1929. Zur Embryologie der Tardigraden. Zool. Jahrb. Abt. Anat. Ontogenie Tiere 50, 333-384.

Mayer, G., Martin, C., Rüdiger, J., Kauschke, S., Stevenson, P.A., Poprawa, I., Hohberg, K., Schill, R.O., Pflüger, H.-J., Schlegel, M., 2013. Selective neuronal staining in tardigrades and onychophorans provides insights into the evolution of segmental ganglia in panarthropods. BMC Evol. Biol. 13, 230.

McGreevy, K.M., Heikes, K.L., Kult, S., Tharp, M.E., Goldstein, B., 2018. Fluorescent Cell Staining Methods for Living Hypsibius exemplaris Embryos. Cold Spring Harb. Protoc. 2018, 878-884. https://doi.org/10.1101/pdb.prot106021

McNuff, R., 2018. Laboratory Culture of Hypsibius exemplaris. Cold Spring Harb. Protoc. 2018 867-870. https://doi.org/10.1101/pdb.prot102319

Møbjerg, N., Jørgensen, A., Kristensen, R.M., Neves, R.C., 2018. Morphology and Functional Anatomy, in: Schill, R.O. (Ed.), Water Bears: The Biology of Tardigrades. Springer, Cham, pp. 57-94.

Nakahara, Y., Imanishi, S., Mitsumasu, K., Kanamori, Y., Iwata, K.-I., Watanabe, M., Kikawada, T., Okuda, T., 2010. Cells from an anhydrobiotic chironomid survive almost complete desiccation. Cryobiology 60, 138-146.

Nelson, D.R., 2017. Cytochrome P450 diversity in the tree of life. Biochim. Biophys. Acta: Proteins Proteomics 1866, 141-154.

Nkem, J.N., Wall, D.H., Virginia, R.A., Barrett, J.E., Broos, E.J., Porazinska, D.L., Adams, B.J., 2006. Wind dispersal of soil invertebrates in the McMurdo Dry Valleys, Antarctica. Polar Biol. 29, 346-352.

Patel, N.H., 1994. Developmental evolution: insights from studies of insect segmentation. Science 266, 581-590.

Piszkiewicz, S., Gunn, K.H., Warmuth, O., Propst, A., Mehta, A., Nguyen, K.H., Kuhlman, E., Guseman, A.J., Stadmiller, S.S., Boothby, T.C., Neher, S.B., Pielak, G.J., 2019. Protecting activity of desiccated enzymes. Protein Science 28, 941-951. https://doi.org/10.1002/pro.3604

Ptatscheck, C., Gansfort, B., Traunspurger, W., 2018. The extent of wind-mediated dispersal of small metazoans, focusing nematodes. Sci. Rep. 8, 6814.

Ramazzotti, E., Maucci, W., 1995. The Phylum Tardigrada. Translated by C.W. Beasley.

Rebecchi, L., Altiero, T., Guidetti, R., Cesari, M., Bertolani, R., Negroni, M., Rizzo, A.M., 2009. Tardigrade Resistance to Space Effects: First Results of Experiments on the LIFE-TARSE Mission on FOTON-M3 (September 2007). Astrobiology 9, 581-591. https://doi.org/10.1089/ast.2008.0305

Richaud, M., Le Goff, E., Cazevielle, C., Ono, F., Mori, Y., Saini, N.L., Cuq, P., Baghdiguian, S., Godefroy, N., Galas, S., 2020. Ultrastructural analysis of the dehydrated tardigrade Hypsibius exemplaris unveils an anhydrobiotic-specific architecture. Sci. Rep. 10, 4324.

Rivas, J.A., Jr, Schröder, T., Gill, T.E., Wallace, R.L., Walsh, E.J., 2019. Anemochory of diapausing stages of microinvertebrates in North American drylands. Freshw. Biol. 64, $1303-1314$.

Schill, R.O., 2018. Water Bears: The Biology of Tardigrades. Springer, Switzerland.

Schill, R.O., Hengherr, S., 2018. Environmental Adaptations: Desiccation Tolerance, in: Schill, R.O. (Ed.), Water Bears: The Biology of Tardigrades. Springer International Publishing, Cham, pp. 273-293.

Sidow, A., Thomas, W.K., 1994. A molecular evolutionary framework for eukaryotic model organisms. Curr. Biol. 4, 596-603.

Smith, F.W., 2018. Embryonic In Situ Hybridization for the Tardigrade Hypsibius exemplaris. 
Cold Spring Harb. Protoc. 2018, 891-899. https://doi.org/10.1101/pdb.prot102350

Smith, F.W., Bartels, P.J., Goldstein, B., 2017. A Hypothesis for the Composition of the Tardigrade Brain and its Implications for Panarthropod Brain Evolution. Integr. Comp. Biol. 57, 546-559.

Smith, F.W., Boothby, T.C., Giovannini, I., Rebecchi, L., Jockusch, E.L., Goldstein, B., 2016. The Compact Body Plan of Tardigrades Evolved by the Loss of a Large Body Region. Curr. Biol. 26, 224-229.

Smith, F.W., Cumming, M., Goldstein, B., 2018. Analyses of nervous system patterning genes in the tardigrade Hypsibius exemplaris illuminate the evolution of panarthropod brains. Evodevo 9, 19.

Smith, F.W., Gabriel, W.N., 2018. Embryonic Immunostaining for the Tardigrade Hypsibius exemplaris. Cold Spring Harb. Protoc. 2018, 885-890. https://doi.org/10.1101/pdb.prot102343

Smith, F.W., Goldstein, B., 2016. Segmentation in Tardigrada and diversification of segmental patterns in Panarthropoda. Arthropod Struct. Dev. 46, 328-340.

Smith, F.W., Jockusch, E.L., 2014. The metameric pattern of Hypsibius dujardini(Eutardigrada) and its relationship to that of other panarthropods. Front. Zool. 11, 1-16.

Sogame, Y., Kikawada, T., 2017. Current findings on the molecular mechanisms underlying anhydrobiosis in Polypedilum vanderplanki. Current Opinion in Insect Science 19, 16-21. https://doi.org/10.1016/j.cois.2016.10.008

Sommer, R.J., 2000. Evolution of nematode development. Current Opinion in Genetics \& Development 10, 443-448. https://doi.org/10.1016/s0959-437x(00)00110-6

Suzuki, A.C., 2008. Appearance of males in a thelytokous strain of Milnesium cf. tardigradum (Tardigrada). Zoolog. Sci. 25, 849-853.

Suzuki, A.C., 2003. Life History of Milnesium tardigradum Doyère (Tardigrada) under a Rearing Environment. Zoological Science 20, 49-57. https://doi.org/10.2108/zsj.20.49

Tanaka, S., Tanaka, J., Miwa, Y., Horikawa, D.D., Katayama, T., Arakawa, K., Toyoda, A., Kubo, T., Kunieda, T., 2015. Novel Mitochondria-Targeted Heat-Soluble Proteins Identified in the Anhydrobiotic Tardigrade Improve Osmotic Tolerance of Human Cells. PLoS One 10, e0118272. https://doi.org/10.1371/journal.pone.0118272

Tenlen, J.R., 2018. Microinjection of dsRNA in Tardigrades. Cold Spring Harb. Protoc. 2018, 900-904. https://doi.org/10.1101/pdb.prot102368

Tenlen, J.R., McCaskill, S., Goldstein, B., 2013. RNA interference can be used to disrupt gene function in tardigrades. Dev. Genes Evol. 223, 171-181.

Thiruketheeswaran, P., Greven, H., D'Haese, J., 2016. Gelsolin in Onychophora and Tardigrada with notes on its variability in the Ecdysozoa. Comp. Biochem. Physiol. B Biochem. Mol. Biol. 203, 47-52.

Thomas, C., DeVries, P., Hardin, J., White, J., 1996. Four-dimensional imaging: computer visualization of 3D movements in living specimens. Science 273, 603-607.

Tsujimoto, M., Suzuki, A.C., Imura, S., 2015. Life history of the Antarctic tardigrade, Acutuncus antarcticus, under a constant laboratory environment. Polar Biol. 38, 1575-1581.

Vasanthan, T., Stone, J., 2020. Life history traits for the freshwater Tardigrade Species Hypsibius exemplaris reared under laboratory conditions. J. Wildlife and Biodiversity 4, 6572.

von Erlanger, R., 1895. Beiträge zur Morphologie der Tardigraden. I. Zur Embryologie eines Tardigraden: Macrobiotus macronyx Dujardin. Morphol Jahrb 22, 491-513.

von Wenck, W., 1914. Entwicklungsgeschichtliche Untersuchungen an Tardigraden (Macrobiotus lacustris Duj.). Zool Jb Anat 37, 465-514.

Wojciechowska, D., Roszkowska, M., Kaczmarek, Ł., Jarmuszkiewicz, W., Karachitos, A., Kmita, H., 2021. The tardigrade Hypsibius exemplaris has the active mitochondrial alternative oxidase that could be studied at animal organismal level. PLoS One 16, 
e0244260.

Wright, J.C., 1989. Desiccation Tolerance and Water-Retentive Mechanisms in Tardigrades. Journal of Experimental Biology 142, 267-292. https://doi.org/10.1242/jeb.142.1.267

Yamaguchi, A., Tanaka, S., Yamaguchi, S., Kuwahara, H., Takamura, C., Imajoh-Ohmi, S., Horikawa, D.D., Toyoda, A., Katayama, T., Arakawa, K., Fujiyama, A., Kubo, T., Kunieda, T., 2012. Two Novel Heat-Soluble Protein Families Abundantly Expressed in an Anhydrobiotic Tardigrade. PLoS One 7, e44209. https://doi.org/10.1371/journal.pone.0044209

Yoshida, Y., Koutsovoulos, G., Laetsch, D.R., Stevens, L., Kumar, S., Horikawa, D.D., Ishino, K., Komine, S., Kunieda, T., Tomita, M., Blaxter, M., Arakawa, K., 2017. Comparative genomics of the tardigrades Hypsibius dujardini and Ramazzottius varieornatus. PLoS Biol. 15, e2002266.

Yoshida, Y., Sugiura, K., Tomita, M., Matsumoto, M., Arakawa, K., 2019. Comparison of the transcriptomes of two tardigrades with different hatching coordination. BMC Dev. Biol. 19, 24. 


\section{Figures}

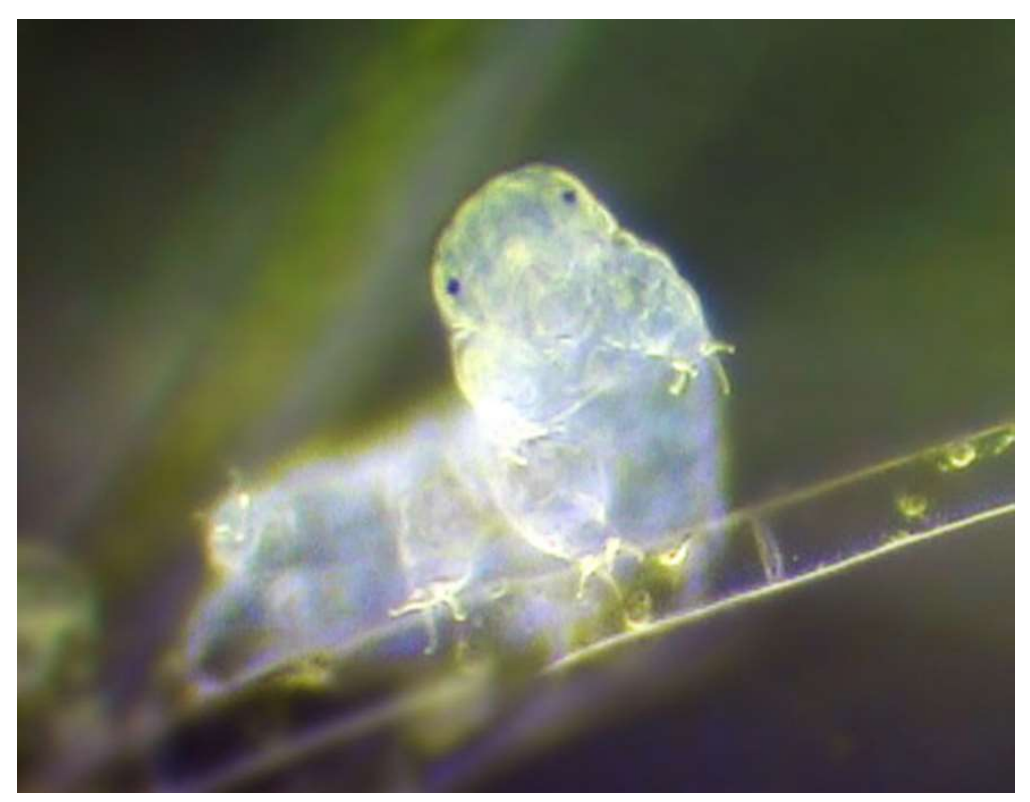

Figure 1. The tardigrade Hypsibius exemplaris. Photo credit: Sinclair Stammers 


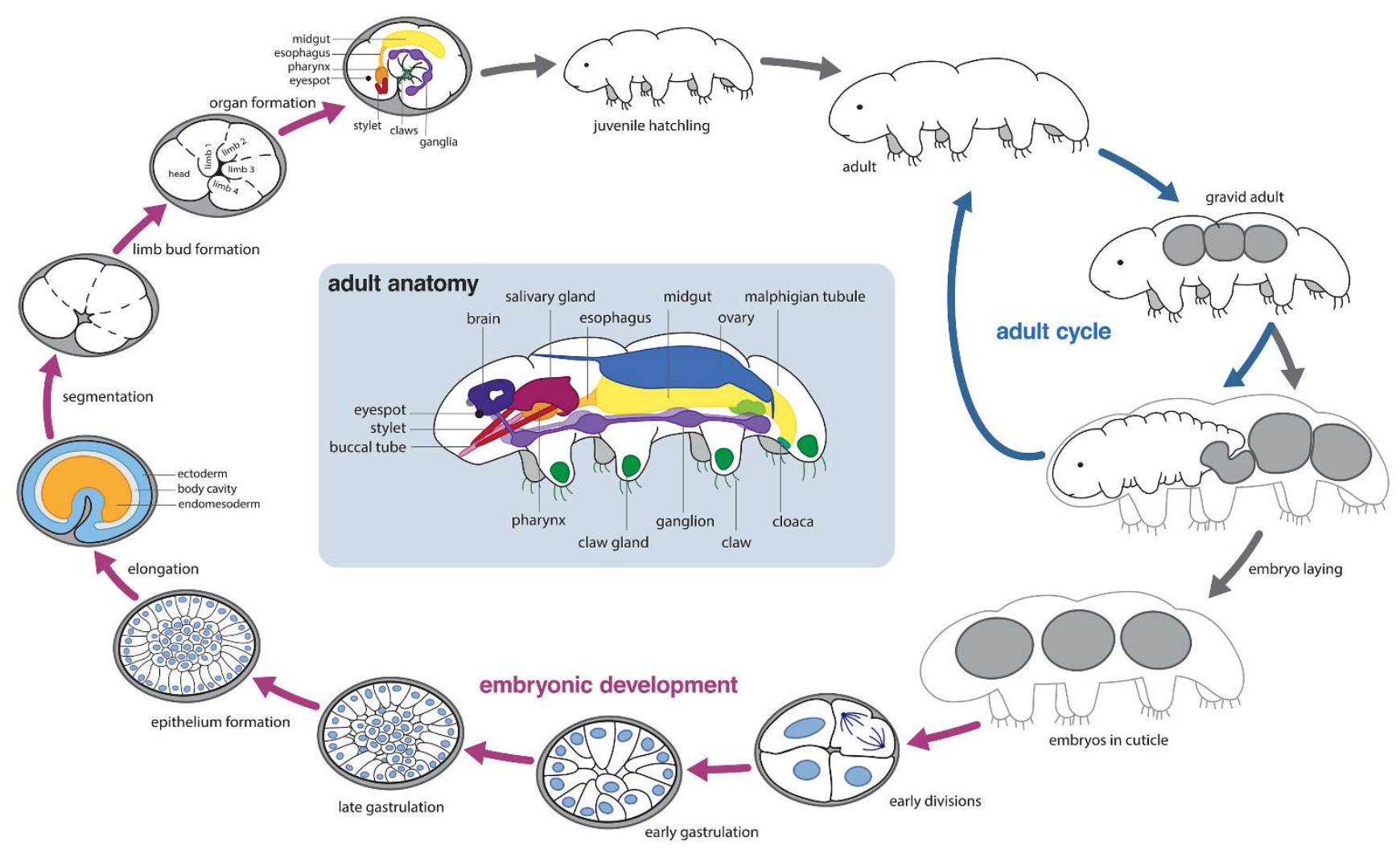

Figure 2. The life cycle and development of Hypsibius exemplaris, and a diagram of adult anatomy. Illustration by Heather Barber. 

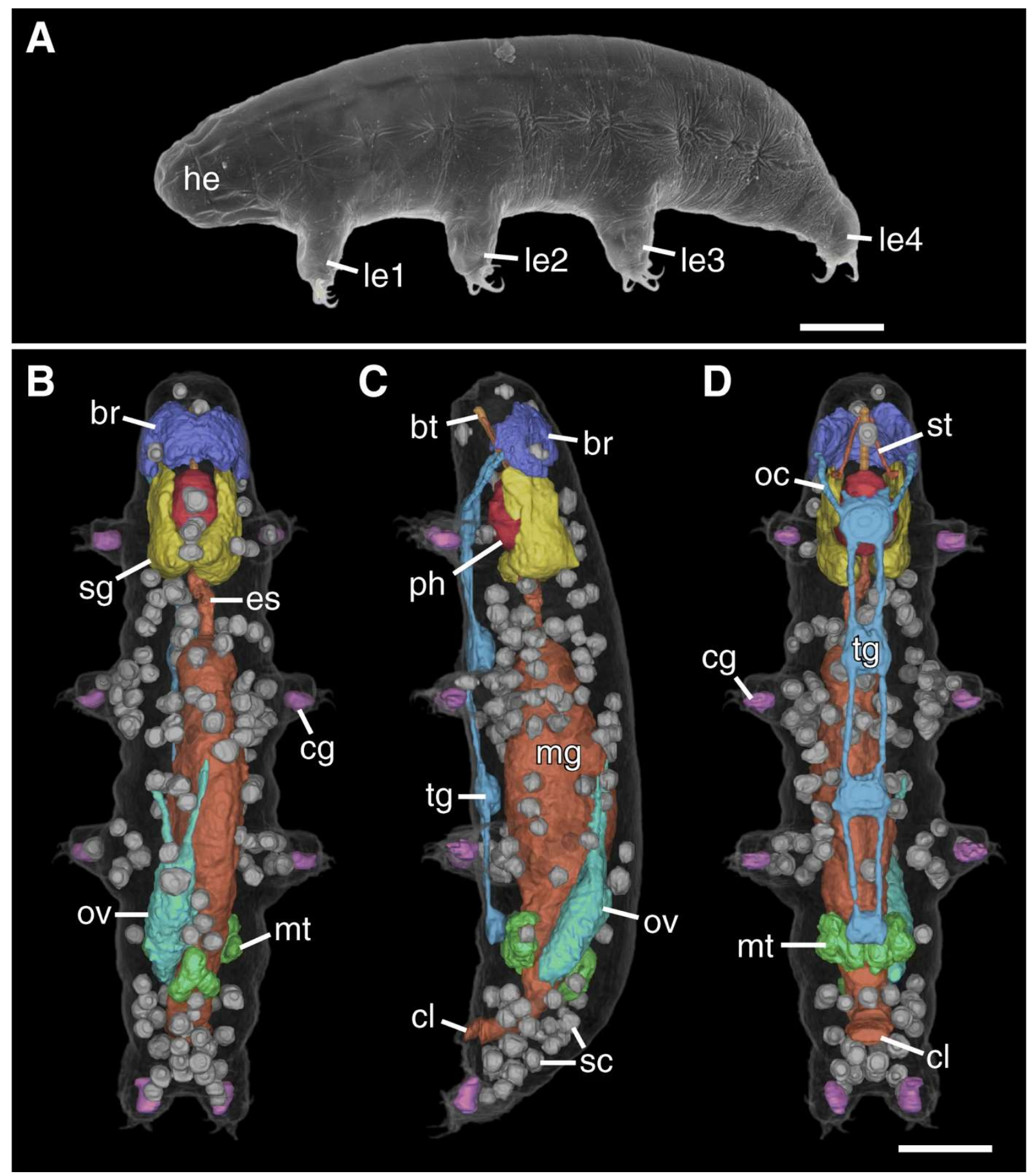

Figure 3. Anatomy of Hypsibius exemplaris: Scanning electron micrograph and 3D renderings of X-ray nanoCT data. (a) Scanning electron micrograph of an adult specimen. Lateral view; anterior is left, dorsal is up. (b-d) 3D renderings of X-ray nanoCT data showing the body in dorsal (b), lateral (c), and ventral (d) views. Anterior is up. Abbreviations: br, brain; bt, buccal tube; cg, claw glands; cl, cloaca; es, esophagus; he, head; le1-le4, leg pairs one to four; mg, midgut; mt, Malpighian tubules; oc, outer connectives; ov, ovary; ph, pharynx; sg, salivary glands; sc, storage cells; tg, trunk ganglion. Scale bars: $20 \mu \mathrm{m}$. From Gross et al., 2019, used with permission. 


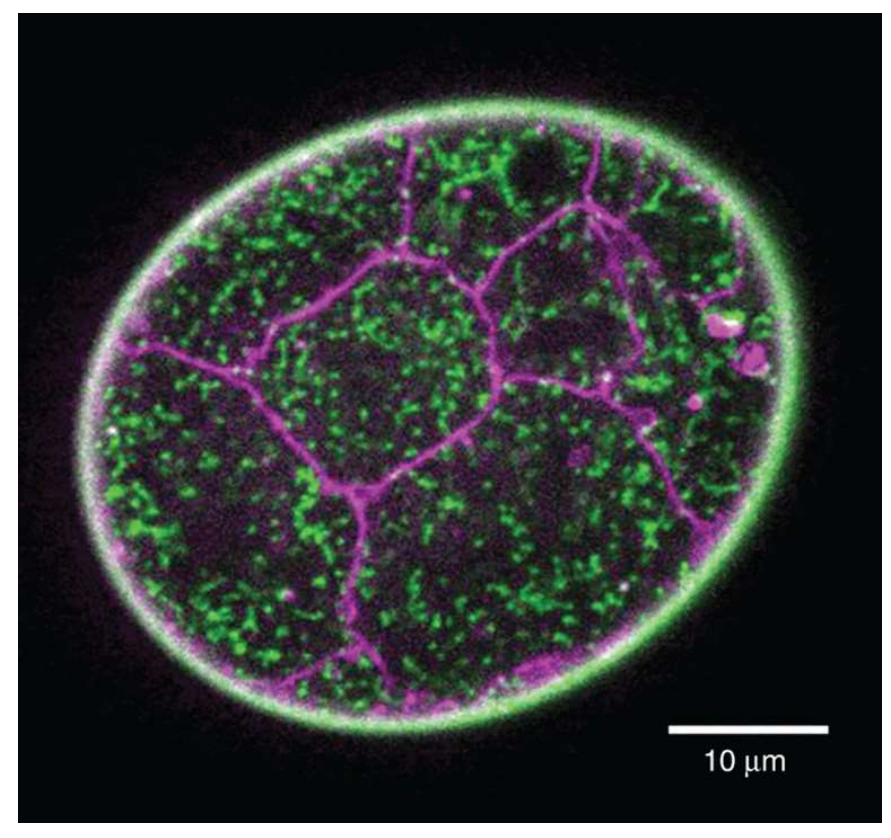

Figure 4. Hypsibius exemplaris embryo with membranes labeled by FM 4-64 (magenta) and mitochondria labeled by Mitotracker Green (green). From McGreevy et al., 2018, used with permission. 


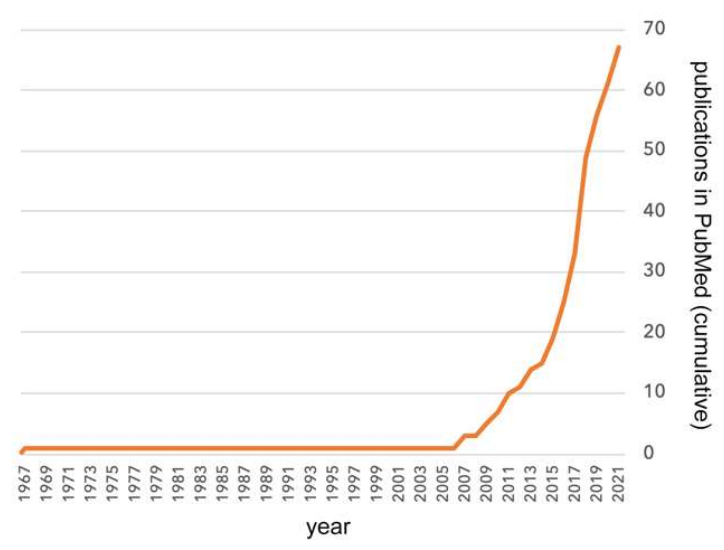

Figure 5. Emergence of Hypsibius exemplaris as a model system. Cumulative number of publications over time in PubMed-indexed journals with Hypsibius dujardini or Hypsibius exemplaris in the title and/or abstract (to date as of 1 November 2021).

Supplemental Video 1. Anatomy of the tardigrade Hypsibius exemplaris. Animated 3D rendering based on X-ray nanoCT data, showing segmentally repeated structures and a flythrough of the original nanoCT volume. From Gross et al., 2019, used with permission. 